\title{
The Research of Library Reader Service under the New Media Environment
}

\author{
Dan Zhao \\ Jilin Agricultural University, Changchun, Jilin Province, China
}

Keywords: New media, Library, Reader service, The network library.

\begin{abstract}
New media and technology to pluralism, personalized interactivity, focus, and across time and space, such characteristics as low cost, for the public library reader service, promotion and propaganda of all kinds of knowledge, information provide a good communication platform. Public library can make full use of new media technology, strengthen the contact with effective communication between readers and users, and give full play to the public library reveal the information of library, develop data resources, the function of the innovative application technology. In this paper, the new media service mode is presented, on the basis of analysis of the public library use of new media service measures and matters needing attention, provide public library reader service work better with a broader communication platform and space.
\end{abstract}

\section{Introduction}

The occurrence of any kind of media technologies are profoundly change the world, television technology to extend people's senses to long distance, the rise of the Internet lead people into the information age, the emergence of the mobile Internet to mobile. Nowadays, new media is constantly in the form of transmission than most people think dominated the flow of information, or even become a kind of new people's existing way. Marshall McLuhan said "medium is the message" and "medium is the extension of man" [1] has become a reality in the modern era of new media.

In such circumstances, the library began to spare no effort to use a variety of new media technology resources construction and service promotion, such as the literature [2] this paper discusses the network media and mobile media application in library service promotion strategy, literature [2] this paper introduces the design and implementation of mobile phone library system scheme, literature [3] using the social network to build a digital library service model. At the same time, technology and humanities of the game is still a subject of debate for a long time people library. This article from the new media's influence on readers, and the new media era the library information service mode and library resources construction quality strategy several aspects are discussed.

\section{The influence of new media to library services}

New media services for the development of library reader service provides convenient at the same time, also brought big challenges. Traditional library collection resources to enrich the advantages of attracting users no longer obvious, the new media information service for the user to obtain more information and offer more convenient way, the traditional point-to-point transmission way is broken, multipoint to multipoint transmission of reticular pattern has gradually become the mainstream form of information transmission [1].

In this case, the development of new media services for the public library reader service brings convenience, brings difficulties and challenges.

Weakening the function of public library information resource library since the ancient times is the preservation of the cultural information, is an important source of public access to information. But with the development of Internet technology, the search engines as part of the new media service, gradually become a very important channel for the public access to information resources, and partly replace the function of the library information resource service. 
The developments of search engine technology, let users have more options in the process of information query. So the public library in the process of reader service of all kinds of activities in the process of using new media means of publicity to give full play to the application of new technology, also remind us of the public library at the same time, must complete the integration of information resources, catalogue, in order to search for use. Reduces the dependence on the library user level only rely more users of public libraries, to make the function of public library play a better reader service [1]. However, the new media service method has gathered from all directions of all kinds of information resources, combined text and image, audio and video resources can not only meet the needs of users' fragmentation reading, also provide users with more vivid reading experience. In addition, some new media services for the user's reading habits were analyzed, and according to user's reading preferences recommend all kinds of information, meet the reading needs of different users.

The new media service users reading rate in ascension, falling on the reliance of the public library users. Users of library depend on the degree of decline, a direct impact on the public library service the number of the target group, also brought challenges for the library reader service.

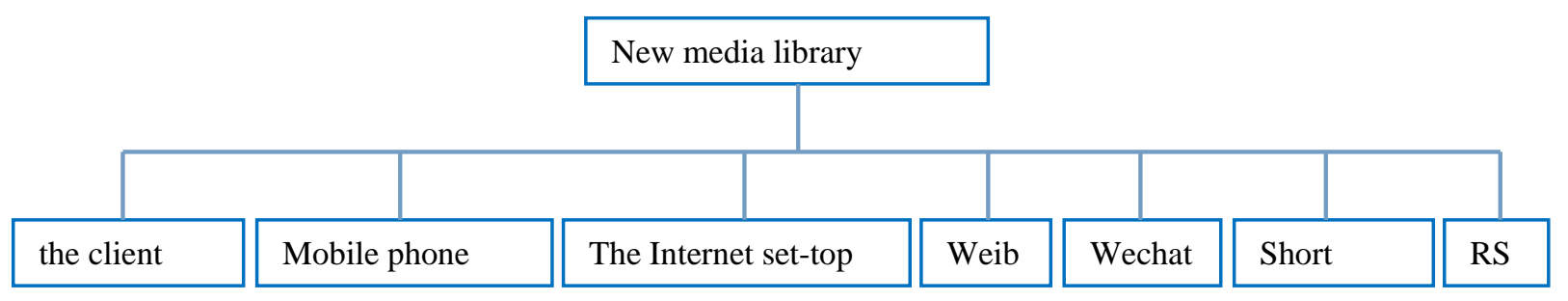

Fig.1 New media library service mode

\section{Library service development strategy under the new media environment}

Reader service work, is refers to the library around the reader in the use of all kinds of requirements, in the process of collection books and the direct service to readers. The basic task of the reader service work is to make full use of library books, maximize meet the needs of readers, including book circulation, publicity, such as reading guidance and reference [2]. Reader service is a service of the work, it must be according to the working direction and tasks, according to the needs of readers, and according to the characteristics and laws of library work, through the publicity and recommendation of the library, books, reading guidance, bibliographic index, answers readers consulting business activities, popularize scientific and cultural knowledge to readers, provides books and materials for scientific research, education and teaching.

For a long time, the public library how to play its proper value easily to serve the public, the use of government investment to build digital publishing platform to serve the society, make the library become citizens of lifelong school, has always been a hot topic in the library industry. In the era of new media, this topic is upgraded to how to make use of advanced technology means to improve the efficiency of the mass reading ability and quickly [2]. Under this background, the public library at all levels shall actively structures, new media platform, and the innovation service form. The library in the use of new media is the main speed up the construction of digital library. Digital library will make through new media library services expand the coverage of the Internet, mobile phones, TV, intelligent mobile terminals, etc. to realize the whole media services. Mobile digital library digital library is the deepening of extension project, the reader can carry mobile phones, electronic readers read anytime and anywhere, and through the wireless network function, the reader can be anywhere in the world to borrow at any time [3]. Not only convenient for readers to read, but also increase the efficiency of the library and the reading rate. Discusses the concrete from the following aspects:

Mining resources enrich the content of the library reader service. As the main body of books stored in public libraries, has a wealth of information resources, how to reasonably mining and the application of the information resources properly is an important task faced by public libraries.

The emergence of new media technology and development, make public library can make full use of cloud computing, big data and other technical service mining resources of library collection 
resources digitization digging, enrich the content of the library reader service, will be the construction of reader service both online and offline.

The new media service mode for reader service more extensive development has provided a broad transmission channel. In deep mining for library resources, on the basis of using the client APP, mobile web, Weibo, WeChat, RSS, digital TV, to share digital collection resources further. Use convenient means of new media increased the majority of readers of the library viscosity, promote the reader service system to improve and perfect [3].

Fully considering the library resources construction characteristics, avoid duplication of development. With the development of library digital resources, all levels of public libraries to digitize collection resources in different degree, but often exist in the process of handling the problem of repeated. Such as the content of the digital resources in municipal public libraries around the pavilion digital content often repeat with local province [4].

Therefore, the public library in the process of using new media in reader service should give full consideration to their own library's characteristics, based on the regional characteristics of development to our region, try to avoid repeat development.

Raise awareness of marketing and promotion of resources and services. With the development of new media technology, most of the library started using APP client, mobile web, Weibo, WeChat platform for propaganda, but each library's push content in a more spontaneous state, lack of independence, in the long run, the overall marketing plan.

In the process of using new media to the reader services, library should abandon the reader service does not require marketing ideas, to recognize the non-profit marketing can also use radio, television, newspapers, magazines and other media push reader service to the public [4]. And besides Weibo library websites, library, to determine the target user, the library can also use E-mail, SMS, WeChat precision marketing, and even use can significantly improve the utilization efficiency of cloud marketing information and information. According to the actual behavior of the user, the user's needs for accurate positioning, mining potential customers, with the help of new media to achieve effective links between reader service with the user.

Trained personnel in public service, promote the development and application of new media technology. Reader service as service behavior citizen centered culture, emphasis on "universality" and "equivalence", requires public library under the principle of "fair" to provide cultural products and services [4]. But with the development of new media technology and the widespread application in the practical work of library, part of the public libraries of "technology first" problem, too much emphasis on librarians on the degree of master of new media technology, that librarians are increasingly become the master "of" new media technology, rather than for the benefit of the concept of "reader service".

In order to better play the primary role of the lead agency for the public library reader service, in the process of reader services in public libraries, should emphasize the cultivation of the "humanistic spirit" of librarians, from the level of social justice and equity to cultivate the humanistic spirit of librarians and the service spirit, only the location of the central position of the user to fully understand their work value, from the heart to make librarians to shoulder the burden of the concept of "reader service disseminator".

\section{Library information service mode of the new media era}

In recent years, with the rapid development of science and technology, new media is more and more get the attention of people. New media is a kind of new industry pattern. It is digital technology, computer technology and modern communication technology development and innovation. New media is a blend of a variety of industrial technology, the development of traditional media and so on related industry has a great impact, and promote the innovation of the industry [5]. The development of the library, for its part, is always accompanied by the development of science and technology and people demand change, the survival and development. Media convergence is becoming a trend; it profoundly changed the way of information transmission. Is gradually increasing because of the new media form appear constantly, influence, lead to the traditional media audience, attention rate and 
books in the library is affected to some extent. To cope with the crisis, we need to know about the reader demand, looking for new way of service to meet their needs. So the library must see trends, to enhance their sense of crisis and the development of consciousness, seized the opportunity to grasp the trend, through a variety of methods and techniques to strengthen the competitive power of the library.

Use the computer technology, network technology, information acquisition way to present a diversified trend. Library as a cultural education institutions and the social literature information center, should broaden the service areas, innovative service concept, strengthening service measures, service content, actively carry out based on the deep service of network information resources and improve the efficiency of the library service, expand the cohesion of the library services.

Mobile information services. Mobile information service refers to the Internet, relying on the mature wireless mobile network, and new media technology users is not limited by time, space and place, through a variety of convenient mobile devices such as mobile phones, handheld reader such as flexible and convenient to browse and query of information and access to the service of information resources [5]. The flexibility of mobile information services for its access to information will become the main form of the development of the future library information service, including the reader status query, SMS notification, reference, database retrieval, guide readers to browse and literature full-text access download, etc. The rapid development of mobile technology, greatly improve the ability of library's information service, readers by using the network platform can easily use wireless link technology, mobile wireless open library information service.

Digital reference service. Digital reference in the era of new media is a comprehensive resource, technology, service system, it is involved in sharing knowledge and concept, combining information service and reader demand real environment, and with the environment change and adjust the mode of information service. Such as visual consulting, online consulting, interactive, real-time, etc. , provide readers with dynamic, real-time and efficient service [6]. The main form of real-time interactive, experts, asynchronous, collaborative digital reference service, including collaborative consultation service, the most characteristic and most representative, it is composed of multiple joint formation of the distributed virtual libraries and information institutions information consulting service network, with many institutions of library information resources and the huge network information resources as the backing, in order to reference librarian and subject expert of the institutions as a backing, on the global network to build Bridges, through the digital information reference system, put forward problem for any time, any place any reader information reference service.

Readers individualized information service. Readers is the library individualized information service under the new media environment, individualized information demand of intelligent analysis on readers and active to push and tracking service. Personalized information service for readers in general for the personalized demand custom interactive service plan, use a variety of data analysis technology, in a timely manner to the readers the active and accurately provide the required information resources, and according to the readers' feedback modification, perfect and recommend the results, improve the service quality and level [6]. Set according to the individual needs of readers service way, with the aid of the application of the new media technology to collect information, access and transmission, and finally achieve the goal of innovation and utilization of information resources Including personalized information push, personalized intelligent agent, individualized information customization, personalized service content such as data mining.

Digital TV library services. Today the development of the library information service in digital TV has been further extension of the library can take advantage of the digital TV interactive function, develop the corresponding interface, connect digital TV and digital library readers through the digital TV to be able to enjoy the advantages of digital library service, such as query their borrowing situation, retrieval, the library collection resources, read electronic books, booking and renew books, enjoy video library, on demand, listen to classic dramas library virtual lecture, etc [6]. At present, in the digital TV set up columns the library has a lot of, such as the national library, Tianjin, Shenzhen, Hangzhou, Shanghai library etc., which produced by the national library digital TV "state map space", 
including the one hundred state map, books recommended, collection boutique, Wenjin forum, encyclopedia of classic album, drawings and other programs, fully demonstrated the two-way interactive digital library services.

\section{Summary}

The emergence and rapid development of new media constantly changing people's way of information consumption, life style, and even influence people's thinking, the concept of change, will inevitably produce a series of new consumer demand information. As a provider of public cultural products, the library in the process of actively towards a new media everything road, have to stay awake on the change of the mode of transmission of knowledge, with scientific thinking in the new media to re-examine their own service concept and service mode, and constantly adjust, along with the change of age alone, to make the library undertaking in the era of new media to keep exuberant vitality for a long time.

\section{References}

[1] W. Y. Chang, New media services to promote the application in the library. The journal of library, 2007, vol.6, pp.19-21.

[2] X. L. Cheng and Y. Li, bell resolute, Concept, design and application of mobile phone library based on the mobile communication technology, The library theory and practice, 2009, vol.9, pp.63-66.

[3] T. W. Li, Social network and digital library service model, Books intelligence work, 2010, vol. 4, pp. 51-54.

[4] Z. Zh. Wang, The future development of library science rational directions, Journal of library of China, 2013, vol.3, pp. 5-10.

[5] H. X. Sun and H. K. Tao, Traditional library science and modern technology concept of dialectical interpretation, Library journal, 2004, vol. 8, pp.65-69.

[6] Z. X. Wen and L. X. Yuan, Information technology under the impact of library humanistic trend, Work of university library, 2005, vol. 5, pp. 1-6. 